\title{
Desain Aplikasi Restoran Bakmi Ampo Berbasis Web
}

\section{Aprizal Suryaman', Yoni Santoso ${ }^{2}$, Muhammad Mayudin ${ }^{3}$, Anang Mas Akmal ${ }^{4}$, Teti Desyani ${ }^{5}$}

Teknik Informatika, Universitas Pamulang, Tangerang Selatan, Indonesia

E-mail: ${ }^{1}$ aprizalsuryaman9@gmail.com, ${ }^{2}$ noyzcudelta@ gmail.com, ${ }^{3}$ muhammadmayudin12@gmail.com, 4anangakmal10@gmail.com, ${ }^{5}$ dosen00839@unpam.ac.id

Submitted Date: November $17^{\text {th }}, 2020$

Revised Date: March 31 ${ }^{\text {st }}, 2021$
Reviewed Date: November $24^{\text {th }}, 2020$

Accepted Date: April 01 ${ }^{\text {st }}, 2021$

\begin{abstract}
In this study, we will to solve the problem in a bakmi ampo restaurant that still uses manual methods to accept orders. As a result, many orders that come to customers are not suitable. We designed a web-based restaurant application to solve this problem. The method we use is the waterfall method, which is a systematic method for building software through various stages in SDLC. The reason for using the Waterfall method is because this method emphasizes the order in the software development process, after we tried to design the application design, the results were very effective in helping a bakmi ampo restaurant so that orders from customers were not wrong.
\end{abstract}

Keywords: extreme programming; ordering; restaurant; web application

\section{Abstrak}

Di dalam penelitian ini kami akan selesaikan masalah di restoran bakmi ampo yang masih menggunakan cara manual untuk menerima pemesanan, akibatnya banyak pesanan yang datang ke pelanggan tidak sesuai, kami merancang aplikasi restoran berbasis web untuk mengatasi masalah tersebut. Metode yang kami gunakan adalah Metode waterfall merupakan metode sistematis untuk membangun perangkat lunak melalui berbagai tahapan dalam SDLC. Alasan menggunakan metode Waterfall adalah karena metode tersebut menekankan urutan dalam proses pengembangan perangkat lunak, setelah kami mencoba merancang desain aplikasi di dapat hasil sangat efektif untuk membantu restoran bakmi ampo agar pesanan dari pelanggan tidak salah.

Kata kunci: aplikasi web;extreme programming;pemesanan;restoran

\section{Pendahuluan}

Berbisnis adalah salah satu bisnis yang paling menguntungkan bagi para pebisnis. Salah satu contohnya adalah Restoran, restoran adalah tempat atau bangunan organisasi produktif yang memberikan penyajian yang baik terhadap pelanggan atau pengunjung, baik makanan ataupun minuman (Windriyani, 2018). Jasa katering diselenggarakan dalam bentuk menjual makanan dan minuman kepada pelanggan atau pengunjung skala kecil atau besar, untuk memperoleh keuntungan atau membeli dan menjual makanan dan minuman. Biasanya pelanggan atau pengunjung yang datang melakukan transaksi pemesanan makanan dan minuman di restoran tersebut (Defrina \& Lestari, 2017).
Begitu mudah kita temukan rumah makan atau restoran yang menyajikan berbagai menu untuk menarik pelanggan atau pengunjung. Bakmi Ampo Restaurant adalah restoran yang berada di Jakarta. Restoran ini berdiri sejak tahun 2014 dan nama restoran ini diambil dari makanan khas daerah Gunung Kidul. Sebagai pesaing baru di industri katering, restoran Bakmi Ampo haruslah menjadi restoran yang memberikan pelayanan terbaik bagi pelanggan atau pengunjung, baik itu untuk pelanggan atau pengunjung dalam menyediakan makanan, minuman atau tempat yang nyaman (Inayati, 2015).

Restoran Bakmi Ampo akan terus bekerja keras untuk memberikan kualitas pelayanan yang lebih baik kepada pelanggan dan meningkatkan pendapatan atau meningkatkan 
keuntungan, ini merupakan salah satu cara pemanfaatan teknologi informasi untuk mendukung bisnis restoran (Nugroho \& Djajalaksana, 2015). Selain itu, pelanggan melakukan pemesanan melalui daftar menu, dan terkadang terjadi kesalahan saat menulis pesanan antara pelanggan dengan staf restoran Bakmi Ampo (Utama, Johar, \& Coastera, 2016).

Berdasarkan permasalahan di atas maka penulis akan menggunakan bahasa pemrograman hypertext preprocessor untuk merancang sistem informasi pemesanan menu makanan, serta membuat halaman menu dan harga makanan serta data transaksi bagi pengunjung (Gunawan, Hastuti, Andriani, \& Susafa'ati, 2018). Semoga aplikasi ini dapat mempermudah tanggung jawab karyawan dalam mengolah data pengunjung dan data transaksi.

Pengguna aplikasi ini terdiri dari dua jenis pengguna, yaitu pelanggan dan administrator. Aplikasi pelanggan memiliki 2 tampilan yaitu tampilan layar untuk pemesanan makanan dan minuman, dan tampilan layar pelanggan juga dapat melihat harga dan kuantitas yang dipesan. Aplikasi administrator sendiri memiliki 3 tampilan yaitu: tampilan untuk menambah dan mengganti menu yang tersedia, tampilan untuk melihat harga makanan yang dipesan oleh pelanggan, dan tampilan untuk melihat laporan transaksi setiap hari.

\section{Metodologi}

Metode penelitian dalam mendesain aplikasi pada Resto Bakmi Ampo adalah dengan menggunakan model Waterfall. Metode waterfall merupakan metode sistematis untuk membangun perangkat lunak melalui berbagai tahapan dalam SDLC (Kusnawi, 2013). Alasan menggunakan metode Waterfall adalah karena metode tersebut menekankan urutan dalam proses pengembangan perangkat lunak. Metode tersebut merupakan salah satu cara yang membuat aplikasi yang tidak banyak melibatkan sumber daya manusia (Sugiarto \& Haryadi, 2006). Metode ini mencakup empat tahap:

1. Analisis kebutuhan perangkat lunak

Melalui diskusi dan wawancara dengan karyawan Resto Bakmi Ampo dan pelanggan atau pengunjung Resto Bakmi Ampo, kebutuhan perangkat lunak dianalisis. Karyawan Resto Bakmi Ampo dan pelanggan Resto Bakmi Ampo akan menggunakan aplikasi ini. Untuk ini, kami membutuhkan data dalam persyaratan sistem mereka. Pengguna tersebut terbagi menjadi dua, yaitu:

a. Administrator

Administrator adalah pengguna yang memiliki akses penuh ke aplikasi. Administrator juga mengelola data transaksi pelanggan, penjualan makanan dan transaksi keuangan.

b. Pengguna umum

Pengguna biasa adalah pelanggan Resto Bakmi Ampo, mereka bisa melihat atau memesan makanan di Resto Bakmi Ampo. Pengguna biasa tidak memiliki akses untuk berhak mengubah atau menambah data, kecuali mengubah pesanan makanan yang akan dipesan di Resto Bakmi Ampo

2. Desain

Setelah mendapatkan analisis kebutuhan perangkat lunak, selanjutnya dilakukan perancangan website sesuai dengan spesifikasi analisis yang diperoleh. Perancangan tampilan layar dilakukan setelah mendapatkan analisis kebutuhan perangkat lunak dan perancangan website berdasarkan analisis.

\section{Use Case Diagram}

Skema use case diagram menunjukkan interaksi antara peserta dan sistem yang dibuat (Wirdada, 2014). Interaksi yang dilakukan oleh peserta memiliki bentuk fungsional, dan peserta ini dapat tampil sambil menggunakan sistem. Skema Use case dapat dipakai sebagai arahan untuk siapapun yang memiliki hak akses pada sistem dan hak apa yang tersedia (Nugraha \& Satoto, 2014). Diagram penggunaan yang ditunjukkan di bawah ini menunjukkan interaksi antara peserta dan tindakan yang mereka lakukan. Pelanggan dalam sistem dapat memesan makanan, meminta bantuan dan membayar, sementara karyawan dapat melakukan transaksi pesanan dan transaksi pembayaran. Karyawan bisa menambah, memperbarui, dan menghapus pengguna. Selain itu, menu makanan dan menu minuman dapat diatur oleh karyawan. Karyawan bisa mengelola laporan penjualan dan 
karyawan harus masuk untuk mengakses sistem.

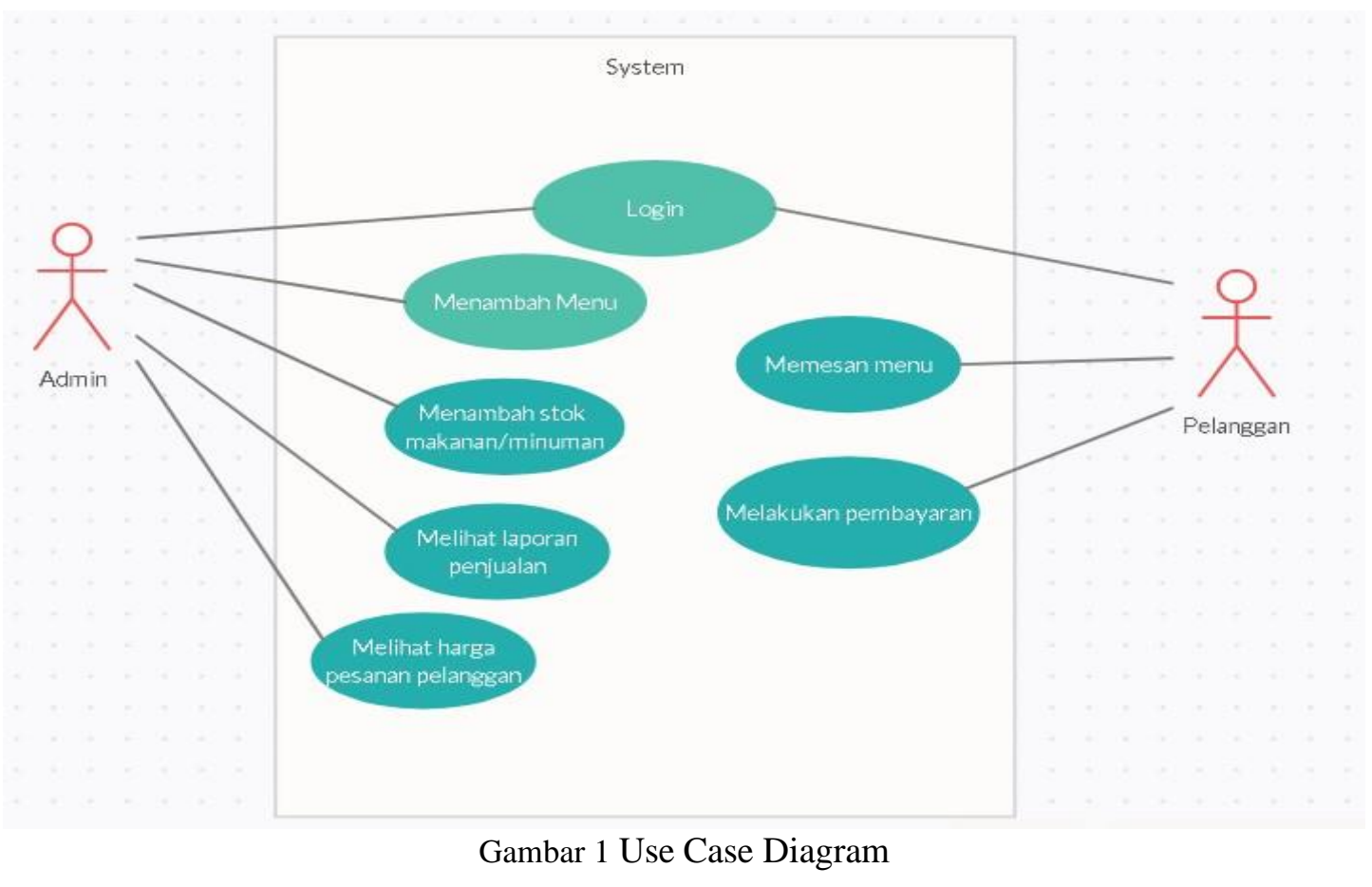

3. Implementasi

Bahasa pemograman yang kita gunakan adalah bahasa pemograman PHP yang diimplementasikan untuk website aplikasi pemesanan makanan yang dirancang dengan bootstrap 4.0. Susunan implementasi merupakan rancangan sistem yang dijabarkan melalui pemilihan perangkat keras dan susunan kerangka koding. Untuk penjabarannya kita memasukan desain bootstrap pada server yang disediakan oleh pihak resto bakmi ampo.

4. Uji Coba

Untuk menjamin kualitas sistem/aplikasi yang dikembangkan harus melalui tahap uji coba (Pratala, Asyer, Prayudi, \& Saifudin, 2020). Uji coba merupakan suatu rangkaian aktivitas yang terencana dan sistematis untuk menguji atau mengevaluasi kebenaran fungsi aplikasi berdasarkan desain kasus uji (test case) yang spesifik (Yulistina, Nurmala, Supriawan, Juni, \& Saifudin, 2020). Uji coba terhadap perangkat lunak sangat penting dilakukan dengan tujuan untuk memberikan jaminan kualitas perangkat lunak yang dihasilkan agar bebas dari terjadinya kesalahan (Debiyanti, Sutrisna, Budrio, Kamal, \& Yulianti, 2020).

Proses uji coba ini menggunakan sistem uji black box. Metode pengujian black box adalah pengujian yang memverifikasi hasil eksekusi aplikasi berdasarkan masukan yang diberikan (data uji) untuk memastikan fungsional dari aplikasi sudah sesuai dengan persyaratan (requirement) (Febrian, Ramadhan, Faisal, \& Saifudin, 2020). Berdasarkan detail aplikasi, tampilan, dan fungsi pada aplikasi dilakukan pengujian pada black box test, dan apakah fungsi tersebut sudah sesuai dengan sistem yang dibutuhkan pelanggan atau pengunjung. Uji coba black box merupakan pengujian tampilan atau antarmuka suatu aplikasi agar mudah digunakan untuk mengunjungi pelanggan atau pengunjung. Tes berikut tidak akan melihat kode sumber aplikasi. Pengujian black box bekerja dengan mengabaikan struktur kontrol, sehingga hanya berfokus pada domain. Misalnya penambahan, update dan penghapusan sistem navigasi, login, program, data dan fasilitas lainnya. Teknologi pengujian kotak hitam dapat 
memperoleh sekumpulan data hasil, yang memenuhi ketentuan fungsi pada program. Sistem uji coba harus beroperasi sesuai dengan yang diinginkan.

5. Operasi dan pemeliharaan (maintenance)

Selain itu, tahap pengoperasian dan pemeliharaan merupakan tahap terakhir. Aplikasi ini dipublikasikan secara online di Internet dan mulai digunakan. Agar aplikasi dapat berjalan normal, diperlukan pemeliharaan sistem secara teratur.

\section{Analisis Break Even Point}

Break Event Point (BEP) merupakan pendapatan dan jumlah biaya yang seimbang, maka perusahaan tidak akan mengalami untung atau rugi. Analisis hubungan impas dan biayakuantitas-laba merupakan suatu teknik perencanaan laba jangka pendek yang didasarkan pada analisis perubahan pendapatan atau biaya penjualan dengan jumlah aktivitas.

Tetapi perusahaan tidak akan memperoleh keuntungan, sehingga terdapat neraca pembayaran. Biasanya, perusahaan hanya menggunakan biaya operasional dan penjualan yang cukup untuk menutupi biaya operasional dan biaya marjinal.

Biaya tetap dan biaya variabel ditentukan oleh analisis break even point (BEP). Biaya tetap mengacu pada biaya yang jumlah keseluruhannya tetap dan meningkat yang mengalami perubahan volume aktivitas. Biaya variabel mengacu pada biaya yang jumlah keseluruhannya berubah dengan perubahan volume aktivitas. Gambar di bawah ini merupakan hasil dari Software Development Life Cycle (SDLC) dan break even point.

Benefits
\begin{tabular}{|l|r|}
\hline \multicolumn{1}{|c|}{ Name } & Total \\
\hline Increased Sales & Rp 250.000 \\
\hline Improved Customer Service & Rp 50.000 \\
\hline Reduced Inventory Costs & Rp50.000 \\
\hline Total Benefits & Rp 350.000 \\
\hline
\end{tabular}

Development costs
\begin{tabular}{|l|r|}
\hline \multicolumn{1}{|c|}{ Name } & Total \\
\hline Domain & Rp 100.000 \\
\hline printer & Rp 300.000 \\
\hline Software Lincenses & Rp 150.000 \\
\hline server software & Rp 80.000 \\
\hline Development Labor & Rp 600.000 \\
\hline Total Development cost & Rp 1.230 .000 \\
\hline
\end{tabular}

Operational Cost
\begin{tabular}{|l|r|}
\hline \multicolumn{1}{|c|}{ Name } & \multicolumn{1}{c|}{ Total } \\
\hline Hardware & Rp 190.000 \\
\hline Software & Rp 180.000 \\
\hline Opertional Labor & Rp50.000 \\
\hline Total Operational Costs & Rp 20.000 \\
\hline \multicolumn{2}{|l|}{ Total Costs } \\
\hline
\end{tabular}

Gambar 2 Software Development Life Cycle (SDLC)

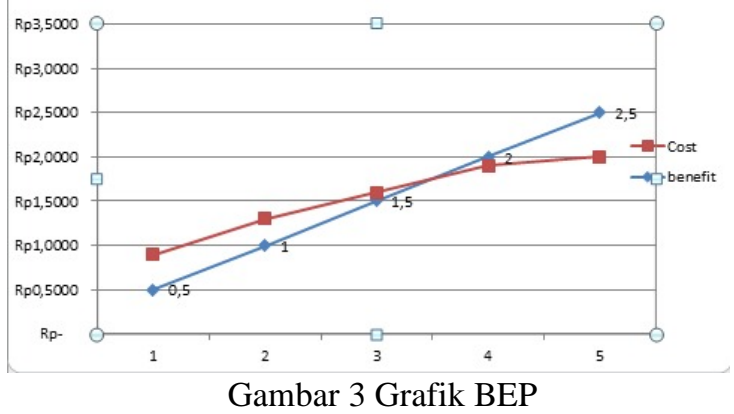

\section{Hasil dan Pembahasan}

Tahap penelitian ini dilakukan untuk mengetahui hasil analisa berupa pengembangan desain aplikasi untuk memesan makanan dan minuman yang ada pada restoran bakmi ampo.

Pertama kali pelanggan singgah dan duduk, Karyawan akan menghampiri pelanggan dan memberikan menu kepada pelanggan. Setelah Pelanggan menerima gadget dari pelayan, pelanggan dapat melakukan beberapa aktivitas yaitu memilih menu yang diinginkan, melakukan pemesanan dan meminta bantuan, seperti terlihat pada Gambar 1. Deskripsi makanan dan minuman akan ditampilkan kepada pelanggan. Uraian tersebut terdiri dari komposisi makanan, pilihan rasa, dan price list untuk setiap item menu. Dari Gambar 1 pelanggan akan menjalankan aktivitas ini secara berurutan sesuai kebutuhan. 


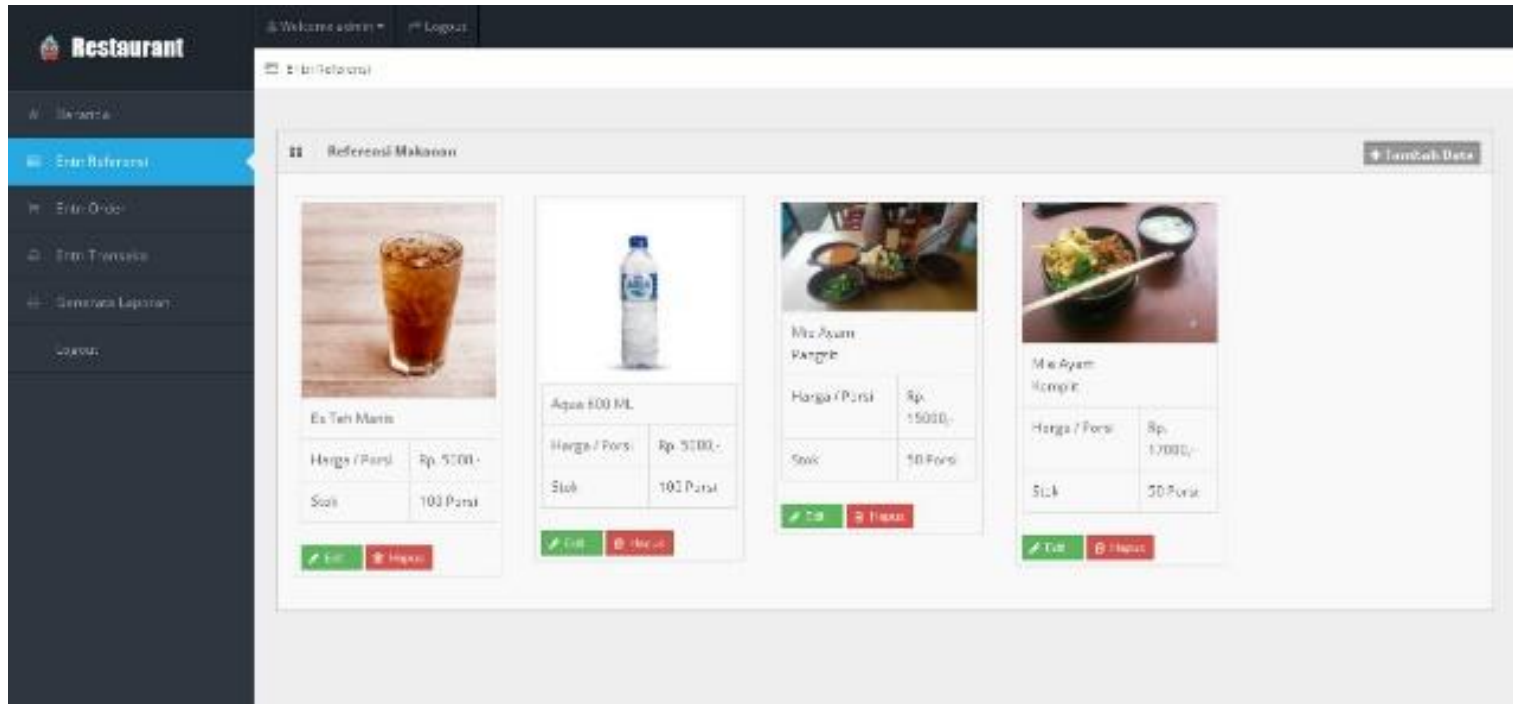

Gambar 4 Tampilan menu

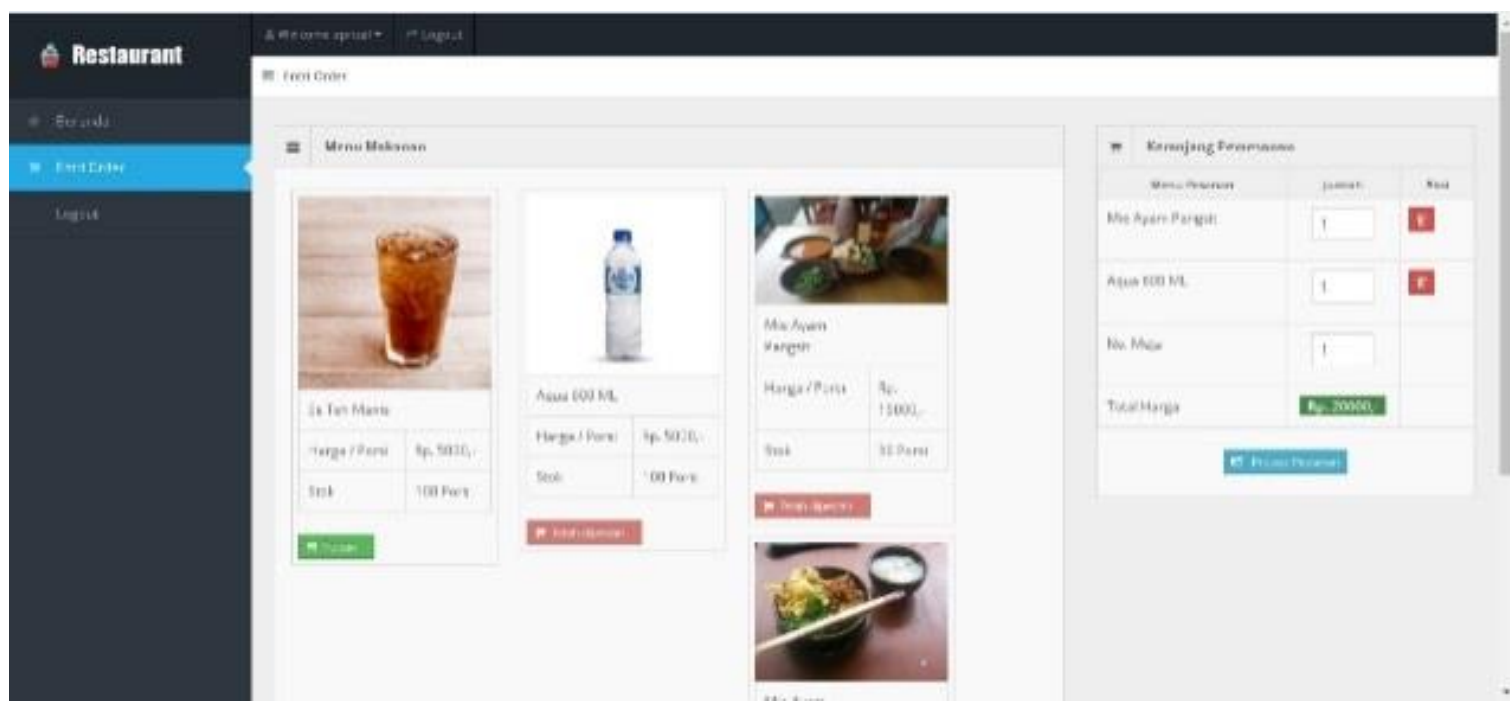

Gambar 5 Tampilan pemesanan

Jika pelanggan sudah memilih pesanan, sistem akan mengulang semua pesanan untuk diproses. Entri order meliputi jenis menu yang diinginkan, jumlah salinan yang diinginkan, dan total harga menu yang harus dibayar pelanggan, seperti yang ditunjukkan pada Gambar 2. Jika pelanggan menekan tombol proses pesanan maka karyawan Bakmi Ampo Resto akan memproses pesanan tersebut. 


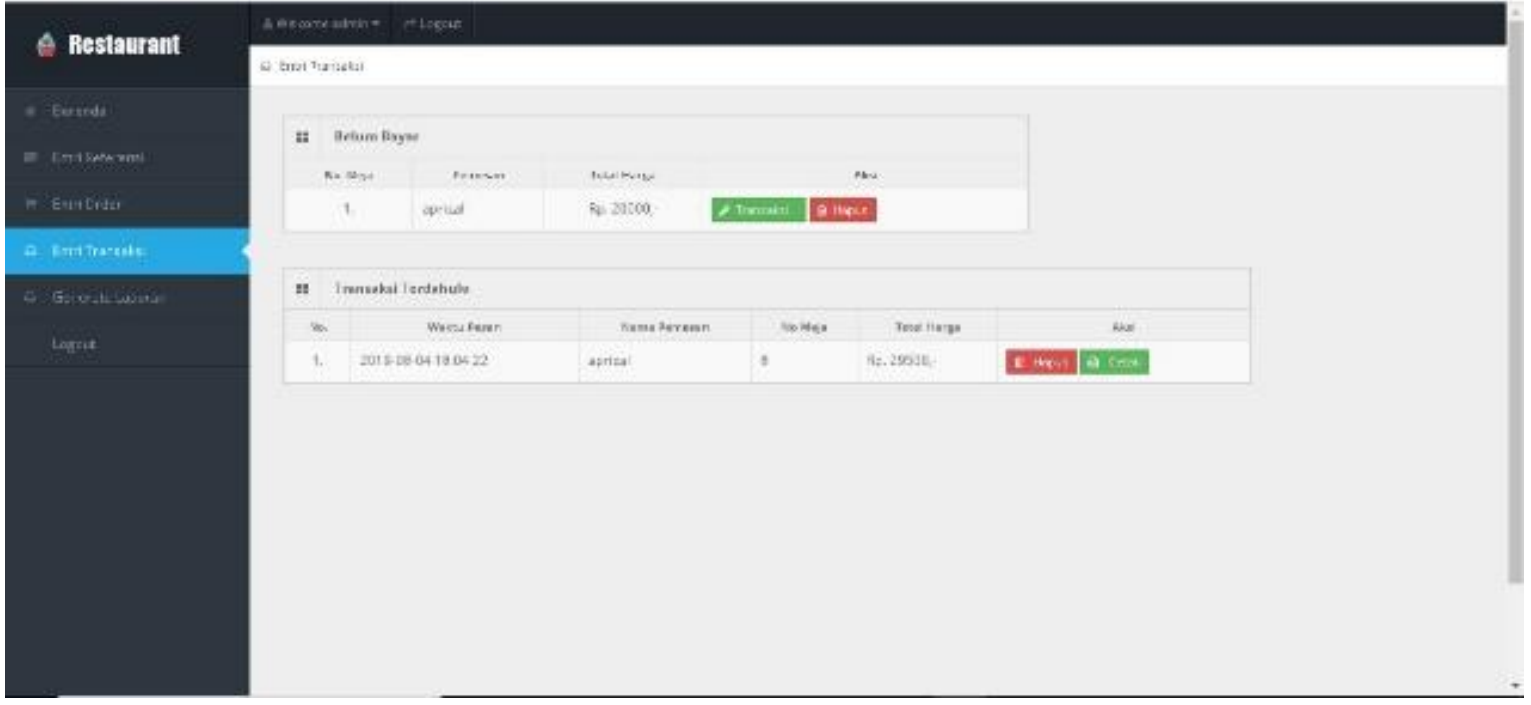

Gambar 6 Tampilan transaksi

Gambar 6 merupakan gambar review penjualan yang dapat diakses karyawan Resto Bakmi Ampo. Ringkasan pesanan di sini menunjukkan berbagai menu yang tersedia, serta jumlah salinan yang diinginkan oleh pelanggan. Karyawan dapat menentukan waktu untuk mengubah urutan, seperti mingguan atau bulanan. Order restatement akan diurutkan berdasarkan penjualan tertinggi ke penjualan terendah. Menu yang tidak terjual tidak akan muncul di daftar menu ringkasan pesanan.

\section{Kesimpulan}

Restoran Bakmi Ampo adalah salah satu restoran yang meningkatkan kualitas dengan memberikan pelayanan yang terbaik kepada pelanggan dan meningkatkan pendapatan serta meningkatkan keuntungan, ini merupakan salah satu cara pemanfaatan teknologi informasi untuk mendukung bisnis restoran.

Dalam membuat desain aplikasi resto bakmi ampo ini kita menggunakan metode yang berbasis web yaitu waterfall, karena metode tersebut menekankan urutan dalam proses pengembangan perangkat lunak. Dan merupakan salah satu cara yang tepat untuk membangun perangkat lunak yang tidak terlalu besar dan melibatkan sumber daya manusia yang terbatas.

Adanya desain aplikasi ini dapat memudahkan pelanggan dan pengguna aplikasi dalam bertransaksi, sepeti pesan makanan dan minuman bagi pelanggan dan dapat melihat laporan penjualan serta melakukan pengecekan transaksi penjualan bakmi ampo bagi penggunanya.

\section{Saran}

Saran bagi penelitian kedepannya untuk dapat mengembangkan dan menambahkan fitur yang lebih baik lagi dari aplikasi sebelumnya, sehingga lebih lengkap dan modern.Seperti fitur untuk mengirimkan pesanan ke bagian kitchen atau koki.

\section{Referensi}

Debiyanti, D., Sutrisna, S., Budrio, B., Kamal, A. K., \& Yulianti, Y. (2020). Pengujian Black Box pada Perangkat Lunak Sistem Penilaian Mahasiswa Menggunakan Teknik Boundary Value Analysis. Jurnal Informatika Universitas Pamulang, 5(2), 162-166. doi:10.32493/informatika.v5i2.5446

Defrina, D., \& Lestari, D. P. (2017). Aplikasi Pemesanan Makanan Online Aplication of Ordering Food and Beverages Online Based on Mobile Browser on Tiga Saudara Restaurant. Jurnal Ilmiah Informatika Komputer, 22(3), 158-170.

Febrian, V., Ramadhan, M. R., Faisal, M., \& Saifudin, A. (2020). Pengujian pada Aplikasi Penggajian Pegawai dengan menggunakan Metode Blackbox. Jurnal Informatika Universitas Pamulang, 5(1), 61-66.

doi:10.32493/informatika.v5i1.4340

Gunawan, D., Hastuti, D. P., Andriani, R., \& Susafa'ati, S. (2018). Sistem Informasi Penjualan Berbasis Web Pada Restoran Caki Cake Karawang. Jurnal Akbar Juara, 3(1), 1-16. 
Inayati, I. (2015). Aplikasi Pemesanan Makanan Berbasis Web (Studi Kasus: RM Lesehan Berkah Ilahi Gresik).

Kusnawi. (2013). Perancangan Sistem Pemesanan Meja dan Makanan (Studi Kasus Restoran ABC).

Nugraha, A., \& Satoto, K. (2014). Aplikasi Pemesanan Makanan Berbasis Mobile Pada Rumah Makan "Lek Nonong". Jurnal Teknologi dan Sistem Komputer,2(2), hlm. 175-180.

Nugroho, J. S., \& Djajalaksana, Y. M. (2015). Aplikasi Web Reservasi dan Penjualan untuk Restoran. Jurnal Sistem Informasi, 9(2), 127-147.

Pratala, C. T., Asyer, E. M., Prayudi, I., \& Saifudin, A. (2020). Pengujian White Box pada Aplikasi Cash Flow Berbasis Android Menggunakan Teknik Basis Path. Jurnal Informatika Universitas Pamulang, $\quad$ 5(2), 111-119. doi:informatika.v5i2.4713

Sugiarto, E., \& Haryadi, I. (2006). Manajemen Kantor Depan Hotel (Hotel Front Office
Management). Jakarta: Gramedia Pustaka Utama.

Utama, D., Johar, A., \& Coastera, F. F. (2016). Aplikasi Pemesanan Makanan dan Minuman Restaurant Berbasis Client Server dengan Platform Android dan PHP menggunakan Metode Centralized DBMS Architecture (Studi Kasus: Cafe Cempakoe Kota Bengkulu). Rekursif : Jurnal Informatika, 4(3), 288-300.

Windriyani, P. (2018). Pengembangan Aplikasi Pemesanan Makanan Dan Minuman di Sebuah Restoran Berbasis Web. 1-7.

Wirdada, S. (2014). Perancangan Sistem Informasi Pemesanan Menu Berbasis Web (Studi Kasus : Coffee Toffee Tembalang, Semarang)

Yulistina, S. R., Nurmala, T., Supriawan, R. M., Juni, S. H., \& Saifudin, A. (2020). Penerapan Teknik Boundary Value Analysis untuk Pengujian Aplikasi Penjualan Menggunakan Metode Black Box Testing. Jurnal Informatika Universitas Pamulang, 5(2), 129-135. doi:10.32493/informatika.v5i2.5366 